\title{
On Forecasting Taiwanese Stock Index Option Prices: The Role of Implied Volatility Index
}

\author{
Jying-Nan Wang ${ }^{1}$, Hung-Chun Liu ${ }^{2} \&$ Lu-Jui Chen ${ }^{3}$ \\ ${ }^{1}$ School of Economics \& Management, Chongqing University of Posts and Telecommunications, China \\ ${ }^{2}$ Department of Finance, Minghsin University of Science \& Technology, Taiwan \\ ${ }^{3}$ Department of International Business, Ming Chuan University, Taiwan \\ Correspondence: Hung-Chun Liu, Department of Finance, Minghsin University of Science \& Technology, No.1, \\ Xinxing Rd., Xinfeng Hsinchu 30401, Taiwan (R.O.C.). Tel: 886-3-559-3142. E-mail: hungchun65@ gmail.com
}

Received: June 20, 2017

Accepted: July 27, 2017

Online Published: August 20, 2017

doi:10.5539/ijef.v9n9p133

URL: https://doi.org/10.5539/ijef.v9n9p133

\begin{abstract}
This paper aims to propose four volatility measures: The first is the GARCH model advocated by Bollerslev (1986); the second is the GARCH $\mathrm{VIX}_{\mathrm{V}}$ model which extends the GARCH model by including the volatility index (VIX) as explanatory variable for volatility; the last two are $\mathrm{HS}_{20 \mathrm{D}}$ and $\mathrm{HS}_{252 \mathrm{D}}$, which represent the historical volatilities generated by traditional rolling window technique with 20- and 252-day historical index returns data, respectively. We examine the price information on VIX to improve the predictive performance of GARCH model for valuing TAIEX stock index call options (TXO) over the period from January 2014 to May 2015. Empirical results firstly indicate that both the GARCH and $\mathrm{GARCH}_{\mathrm{VIX}}$ models consistently perform better than the historical volatility models for forecasting call value of TXO under different moneynesses. Secondly, the $\mathrm{GARCH}_{\mathrm{VIX}}$ model significantly outperforms the GARCH model for most cases, indicating that the GARCH-based option price forecasts can be effectively improved with the additional information contained in

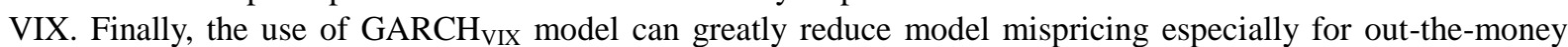
TXO option case. Thus, volatility index is crucial for option traders to efficiently predict TXO option value with GARCH model.
\end{abstract}

Keywords: VIX, TXO, option, BS model, GARCH

\section{Introduction}

Chicago Board Options Exchange (CBOE) develops the volatility index (or VIX) that is derived from the S\&P500 stock index option prices via an option pricing formula in 1993. The VIX has been considered a proxy measure of market's expectation of future stock market volatility over the next 30 day period. Meanwhile, the VIX is also called the fear index or implied volatility index in order to reflect sentiments of investors. The introduction of VIX in 1993 has inspired researchers to explore its practical applications for financial markets.

Chu and Freund (1996) examine the mispricing of option valuation models for a sample of calls on the S\&P 500 and S\&P 100 stock indices when volatility estimates are generated by rolling window historical index returns, GARCH model (Note 1), IGARCH model (Note 2) and index option prices implied volatility. Blair et al. (2001) explore the incremental information content of implied volatilities and intraday returns in the context of forecasting S\&P 100 index volatility over 1 to 20 days forecast horizons. González-Rivera et al. (2004) investigate the forecasting performance of various volatility models for stock returns in terms of several loss functions (including an option pricing function) for which volatility estimation is of paramount importance. We deal with two economic loss functions. Koopman et al. (2005) compare the predictive ability of historical volatility (extracted from daily returns), implied volatility (extracted from option data) and realized volatility (the cumulative sum of squared high frequency returns within a day) for forecasting daily variability of the S\&P 100 stock index returns. Corrado and Truong (2007) augment the GJR-GARCH model of Glosten et al. (1993) by intraday high-low price range and VIX in order to investigate their additional information for improving GJR-GARCH volatility forecasting accuracy. Recently, Wang et al. (2016) propose the augmented GJR model by including various volatility estimators (overnight volatility, daily prices range, and VIX) as explanatory variables for the variance equations in GJR model. These models are used to estimate their daily VaR values for the 
Standard \& Poor's Depositary Receipts (SPDRs). Kim and Ryu (2015) propose a modified value-at-risk (VaR) model that utilizes the implied volatilities extracted from the KOSPI 200 options. They find that the model-free implied volatility index of the KOSPI 200 (VKOSPI) does not greatly enhance the performance of suggested VaR models.

However, despite an extensive literature on volatility forecasting, relatively little research investigates the prices information on VIX to improve the predictive performance of GARCH model for valuing stock index options. This paper aims to use four volatility estimates which are generated by the following models to forecast daily call values of TAIEX options: The first is the GARCH model advocated by Bollerslev (1986); the second is the $\mathrm{GARCH}_{\mathrm{VIX}}$ model which extends the GARCH model by including the VIX as explanatory variable for volatility; the last two are $\mathrm{HS}_{20 \mathrm{D}}$ and $\mathrm{HS}_{252 \mathrm{D}}$, which represent the historical volatilities extracted by traditional rolling window estimation with 20- and 252-day historical index returns data, respectively. We empirically calculate the value of each call on the TAIEX options (TXO) via Black and Scholes (1973)' formula with each of the four volatility estimates, and evaluate their mispricing over the period from January 2014 to May 2015.

The rest of this paper is arranged as follows. Section 2 describes the sample data and Section 3 introduces econometric methodology employed. Section 4 presents the forecasting performance for TXO options under different moneyness cases, while conclusions drawn from this study are also summarized in the same section.

\section{Data}

The data examined in this study comprises of the daily closing prices of Taiwan Weighted Stock Index (TAIEX) and the VIXs of the TAIEX options obtained from the CMONEY database. The sample period for these daily data spans from 2 January 2012 to 29 May 2015 for a total of 839 trading days. The first two years are used as the in-sample period for estimation purpose, while the remaining 1.5 years (343 observations) are taken as the out-of-sample for forecast evaluation. In order to calculate call values of TAIEX options and compare the model mispricing, we also retrieve option data including stock prices, strike prices, maturity day, risk-free rate and settlement prices from the CMONEY database.

Table 1 shows the descriptive statistics of the daily returns for the Taiwan Weighted Stock Index. As shown in Table 1, the average daily return is positive, and approaches close to zero. The returns series exhibits significant evidence of skewness and kurtosis, which means that the series is skewed to the left, and the distribution of the daily returns is more fat-tailed and high-peaked than normal distribution. The J-B test statistic further confirms that the daily returns series is not normal distribution. Finally, the Ljung-Box test statistic exhibits linear dependence for the squared returns and strong ARCH effects.

Table 1. Descriptive statistics of daily returns for the Taiwanese stock index

\begin{tabular}{cccccccc}
\hline Mean $(\%)$ & Std. & Min. & Max. & Skew. & Kurt. & JB & Q $_{s}(12)$ \\
\hline 0.039 & 0.797 & -3.020 & 3.052 & $-0.192^{*}$ & $1.197^{* *}$ & $55.232^{* *}$ & $92.081^{* *}$ \\
\hline
\end{tabular}

Note: JB is the statistic of Jarque and Bera (1987)'s normal distribution test. Q $\mathrm{s}_{\mathrm{s}}(12)$ refers to the Ljung-Box Q test statistic of the squared return series for up to the 12 th order serial correlation. * and ** indicate significance at the $5 \%$, and $1 \%$ levels.

\section{Econometric Methodology}

\subsection{Forecasting Volatility of Underlying Asset Returns}

We augment the GARCH model Bollerslev (1986) with implied volatility as follows:

$$
\begin{gathered}
R_{t}=\mu+\varepsilon_{t}, \quad \varepsilon_{t}=\sigma_{t} z_{t},\left.\quad z_{t}\right|_{\Omega_{t-1}} \sim N I D(0,1) \\
\sigma_{t}^{2}=\omega+\alpha \varepsilon_{t-1}^{2}+\beta \sigma_{t-1}^{2}+\rho V I X_{t-1}
\end{gathered}
$$

where $R_{t}$ is daily return; $\mu$ denotes the conditional mean of returns; $\varepsilon_{t}$ is the innovation process; $z_{t}$ is the standardized residual with zero mean and unit variance; $\sigma_{t}^{2}$ is the conditional variance; VIX $X_{t-1}$ is the implied volatility at the end of TXO options trading on day $t-1$. Thus, marginal contribution of the implied volatility to predicting conditional volatility $\sigma_{t}^{2}$ is measured by the coefficient $\rho$. Obviously, the traditional GARCH model applies the restriction $\rho=0$ to equation (2) with no exogenous regressors.

The annualized standard deviation of the asset returns can be also estimated using historical volatility as follows:

$$
\sigma_{\mathrm{t}, \mathrm{D}}=\sqrt{252} \cdot\left[\frac{1}{\mathrm{D}} \sum_{\mathrm{i}=1}^{\mathrm{D}}\left(\mathrm{R}_{\mathrm{t}-\mathrm{i}}-\overline{\mathrm{R}}\right)^{2}\right]^{0.5}
$$

where $\bar{R}\left(=\frac{1}{D} \sum_{i=1}^{D} R_{t-i}\right)$ denotes the average returns for the past $D$ days, and $D=20$ or 252 . 


\subsection{Black-Scholes Option Price Forecast}

The theoreatical price of an European call option can be directly calculated by Black and Scholes (1976)'s formula as follows:

$$
\begin{gathered}
C_{t, k}=S_{t} \cdot \Phi\left(d_{1, k}\right)-\mathrm{X} \cdot e^{-r_{t}(\tau-t)} \cdot \Phi\left(d_{2, k}\right) \\
d_{1, k}=\frac{\ln \left(\frac{S}{X}\right)+\left(r_{t}+0.5 \cdot \sigma_{t, k}^{2}\right)(\tau-t)}{\sigma_{t, k} \cdot(\tau-t)^{0.5}} \\
d_{2, k}=d_{1, k}-\sigma_{t, k} \cdot(\tau-t)^{0.5}
\end{gathered}
$$

where $C_{t, k}$ denotes the daily forecasting price of TAIEX call options using BS call option formula based on $k$ volatility model at time $t$ that expires in time $(\tau-\mathrm{t}) ; S_{t}$ is the price of Taiwan Stock Exchange Capitalization Weighted Stock Index at time $t ; X$ is the option striking price; $(\tau-\mathrm{t})$ is the call option time to maturity in years; $r_{t}$ is the risk-free interest rate at time $t ; \Phi(\cdot)$ is the cumulative probability density function of the normal distribution; $\sigma_{t, k}$ represents the annualized standard deviation of the index returns forecasted by volatility model, $k$.

\subsection{Evaluation of Forecasting Accuracy}

To examine the option mispricing of four competing models, we calculate mean absolute error (MAE) and mean squared error (MSE) as follows:

$$
\begin{aligned}
& M A E_{k}=\frac{1}{T} \sum_{t=1}^{T}\left|C_{t}^{M P}-C_{t, k}\right| \\
& M S E_{k}=\frac{1}{T} \sum_{t=1}^{T}\left(C_{t}^{M P}-C_{t, k}\right)^{2}
\end{aligned}
$$

where $T$ denotes the number of forecast data points; $C_{t}^{M P}$ denotes the market price of TAIEX call options on day $t$. As shown in Table 2, we examine out-of-sample predictive performance of TAIEX call options across the various models under different moneynesses for empirical illustration.

Table 2. The moneyness of TXO call options

\begin{tabular}{cc}
\hline Case & Moneyness interval \\
\hline In-the-money, ITM & $1.03 \leq \mathrm{S} / \mathrm{X}<1.06$ \\
At-the-money, ATM & $0.97 \leq \mathrm{S} / \mathrm{X}<1.03$ \\
Out-the-money, OTM & $0.94 \leq \mathrm{S} / \mathrm{X}<0.97$ \\
\hline
\end{tabular}

Note. $S$ denotes the price of the underlying stock, and $X$ is the strike price of the stock.

\section{Empirical Results and Conclusions}

Tables 3 presents out-of-sample daily option forecasting performance across the various models by reporting MAE, MSE and Benefit statistics, under at-the-money, out-the-money and in-the-money moneyness cases.

Empirical results indicate that the conditional GARCH-type models consistently perform better than the historical volatility models for forecasting call value of TXO under different moneynesses. Meanwhile, the GARCH $_{\mathrm{VIX}}$ model significantly outperforms the GARCH model for most cases, suggesting that the GARCH-based option price forecasts can be effectively improved with the additional information contained in VIX. In addition, the use of $\mathrm{GARCH}_{\mathrm{VIX}}$ model can vastly reduce model mispricing especially for out-the-money TXO option case. Thus, volatility index is crucial for option traders to efficiently predict TXO option value with GARCH model.

Table 3. Out-of-sample forecasting performance for call values of TAIEX options

\begin{tabular}{ccccccc}
\hline Model & MAE & Rank & Benefit & MSE & Rank & Benefit \\
\hline Panel A. At-the-money case & & & & & & - \\
HS $_{252 \mathrm{D}}$ & 19.2227 & 4 & - & 643.5562 & 4 & $29.07 \%$ \\
HS $_{20 \mathrm{D}}$ & 16.5746 & 3 & $13.78 \%$ & 456.4446 & 3 & $34.54 \%$ \\
GARCH $_{\text {GARCH }}$ & 15.4219 & 2 & $19.77 \%$ & 421.2543 & 2 & $42.19 \%$ \\
\hline Panel B. Out-the-money case & 14.4951 & 1 & $24.59 \%$ & 372.0200 & 1 & - \\
HS $_{252 \mathrm{D}}$ & & & & & \\
HS $_{20 \mathrm{D}}$ & 6.6708 & 4 & - & 90.8518 & 3 & $-5.64 \%$ \\
GARCH $_{\text {GARCH }}$ & 6.2277 & 3 & $6.64 \%$ & 95.9793 & 4 & $44.02 \%$ \\
& 5.2299 & 2 & $21.60 \%$ & 50.8562 & 2 & $64.32 \%$ \\
\hline
\end{tabular}




\begin{tabular}{ccccccc}
\hline Panel C. In-the-money case & & & & & & \\
$\mathrm{HS}_{252 \mathrm{D}}$ & 20.6462 & 4 & - & 757.8975 & 4 & - \\
$\mathrm{HS}_{20 \mathrm{D}}$ & 18.3933 & 3 & $10.91 \%$ & 573.8943 & 3 & $24.28 \%$ \\
GARCH $_{\text {GARCH }}$ & 17.3761 & 1 & $15.84 \%$ & 552.8949 & 2 & $27.05 \%$ \\
\hline
\end{tabular}

Note. 1. MAE and MSE denote the mean absolute error and the mean squared error, respectively. 2. Benefit refers to the percentage forecast error reduction that a forecasting model brings relative to the worst-performing model.

\section{References}

Black, F., \& Scholes, M. (1973). The pricing of options and corporate liabilities. Journal of Political Economy, 81(3), 637-654. https://doi.org/10.1086/260062

Blair, B. J., Poon, S. H., \& Taylor, S. J. (2001). Forecasting S\&P 100 volatility: the incremental information content of implied volatilities and high frequency returns. Journal of Econometrics, 105, 5-26. https://doi.org/10.1016/s0304-4076(01)00068-9

Bollerslev, T. (1986). Generalized autoregressive conditional heteroskedasticity. Journal of Econometrics, 31(3), 307-327. https://doi.org/10.1016/0304-4076(86)90063-1

Chu, S., \& Freund, S. (1996). Volatility estimation for stock index options: A GARCH approach. Quarterly Review of Economics and Finance, 36(4), 431-450. https://doi.org/10.1016/s1062-9769(96)90044-7

Corrado, C., \& Truong, C. (2007). Forecasting stock index volatility: Comparing implied volatility and the intraday high-low price range. Journal of Financial Research, 30(2), 201-215. https://doi.org/10.1111/j.1475-6803.2007.00210.x

Engle, R. F., \& Bollerslev, T. (1986). Modeling the persistence of conditional variances. Econometric Reviews, 5(1), 1-50. https://doi.org/10.1080/07474938608800095

Glosten, L., Jagannathan, R., \& Runkle, D. (1993). On the relation between the expected value and the volatility nominal excess return on stocks. Journal of Finance, 46, 1779-1801. https://doi.org/10.1111/j.1540-6261.1993.tb05128.x

González-Rivera, G., Lee, T., \& Mishra, S. (2004). Forecasting volatility: A reality check based on option pricing, utility function, value-at-risk, and predictive likelihood. International Journal of Forecasting, 20(4), 629-645. https://doi.org/10.1016/j.ijforecast.2003.10.003

Jarque, C. M., \& Bera, A. K. (1987). A test for normality of observations and regression residuals. International Statistics Review, 55, 163-172. https://doi.org/10.2307/1403192

Kim, J. S., \& Ryu, D. (2015). Are the KOSPI 200 implied volatilities useful in value-at-risk models? Emerging Markets Review, 22, 43-64. https://doi.org/10.1016/j.ememar.2014.11.001

Koopman, S., Jungbacker, B., \& Hol, E. (2005). Forecasting daily variability of the S\&P 100 stock index using historical, realised and implied volatility measurements. Journal of Empirical Finance, 12(3), 445-475. https://doi.org/10.1016/j.jempfin.2004.04.009

Wang, J. N., Chen, L. J., Liu, H. C., \& Hsu, Y. T. (2016). Analyzing the downside risk of exchange-traded funds: Do the volatility estimators matter? International Journal of Economics and Finance, 8(1). https://doi.org/10.5539/ijef.v8n1p1

\section{Notes}

Note 1. GARCH refers to the generalized autoregressive conditional heteroskedastic model proposed by Bollerslev (1986).

Note 2. IGARCH refers to the integrated GARCH model of Engle and Bollerslev (1986).

\section{Copyrights}

Copyright for this article is retained by the author(s), with first publication rights granted to the journal.

This is an open-access article distributed under the terms and conditions of the Creative Commons Attribution license (http://creativecommons.org/licenses/by/4.0/). 